Pak. j. sci. ind. res. Ser. A: phys. sci. 201558 (1) 26-33

\title{
Preparation of GF/Wollastonite Reinforced Epoxy Hybrid Composite: Mechanical Properties
}

\author{
Gowkanapalli Ramachandra Reddya, Mala Ashok Kumar*b, Ati Ramesh ${ }^{b}$, \\ Mehaboob Basha $^{c}$, Nadadur Karthikeyan ${ }^{b}$ and Kolimi Madhava Reddyd \\ ${ }^{a}$ Department of Polymer Science \& Technology, Krishnadevaraya University, Anantapur-515055, \\ Andhra Pradesh, India \\ ${ }^{b}$ Department of Mechanical Engineering, Dr. K.V. Subba Reddy Institute of Technology, Dupadu, \\ Kurnool-518218, Andhra Pradesh, India \\ ${ }^{c}$ Department of Mechanical Engineering, Govt. Polytechnic, Anantapur, India \\ ${ }^{d}$ Department of Mechanical Engineering, P.V.K.K. Institute of Technology, Anantapur,
} Andhra Pradesh, India

(received March 18, 2013; revised March 30, 2014; accepted April 3, 2014)

\begin{abstract}
Performance of injection moulded short wollastonite fibre and chopped glass fibre reinforced hybrid epoxy composites was studied. The results showed that hybridisation of glass fibre and wollastonite was in congruence to epoxy glass fibre composite system. Effect of fibre length, fibre orientation in matrix and analysis and fracture surface was undertaken. The mechanical properties of injection moulded, chopped glass fibre/wollastonite/epoxy hybrid composites were investigated by considering the effect of hybridisation by these two fillers. It was observed that the tensile, flexural, and impact properties of the filled epoxy were higher than those of unfilled epoxy. The effect of filler on epoxy matrix subjected to the tensile strength and modulus was studied and compared with the rule of mixture. The actual results are marginally low as compared with the values obtained by the rule of hybrid mixtures (RoHM).
\end{abstract}

Keywords: hybrid fibres, wollastonite, glass fibre, mechanical properties

\section{Introduction}

The persistence of plastics in the environment, shortage of landfill space, concerns over emissions resulting from incineration, and hazards to human health as well as hazards to animals, birds, and fish from entrapment or ingestion of these materials have spurred the efforts to find more environment friendly alternative materials. Various organic/natural fillers reduce the quality of plastic matrix. The hybrid composites reduces pay load and increase in stiffness is important for certain applications for example, satellite and space craft systems. Scientists have explored advantages and disadvantages of hybrid effects in terms of mechanical properties in all these systems. Short fibre composites are attractive structural materials for their relatively ease of processability with respect to resulting flow field and cooling conditions. A complex microstructure may results in different fibre orientations at different points of moulded specimens. Microstructure characteristics can only explain the mechanical properties of short fibre composites. The hybridisation with small amounts of mineral fibres

*Author for correspondence;

E-mail: ashokkumarmala7@hotmail.com makes these glass fibre composites more suitable for technical applications.

In a hybrid system various mechanical properties like stiffness strength and fracture toughness depend on the characteristics of constituent fibres like fibre length and fibre volume fraction. When fibre length is smaller than critical fibre length, fibre pull out takes place but if fibre length is more than critical fibre length breaking of fibre occurs thus fracture mechanisms can be identified with the knowledge of critical fibre length. Epoxy (EP) resin is one of the most important classes of thermosetting polymers which are widely used as matrices for fibre reinforced composite materials and for structural adhesives. They are amorphous, highly cross-linked polymers and these polymers possess various desirable properties such as high tensile strength, modulus, uncomplicated processing and good thermal and chemical resistance and dimensional stability. However, it also leads to low toughness and poor crack resistance, which should be up graded before they can be considered for many end applications. But when filled with mineral and glass fillers, the mechanical properties improve to such an extent of engineering thus enabling them to use 
in engineering applications. The typical reinforcing material used in polymer composites is glass fibre. It is a common reinforcement due to good strength properties, lower price and relatively good adhesion to matrix but now present minerals are in more demand because of a few drawbacks of glass fibres such as lower dispersion, lower thermal and chemical stability and liberation of large amount of heat while processing (Kumar et al., 2011a; 2011b; 2011c; 2010; Mishra and Aireddy, 2011; Dauda et al., 2009; Jayaramudu et al., 2009; Dani et al., 2008; John and Venkata, 2007). Wollastonite is a naturally occurring calcium silicate mineral. Earlier studies have shown that acicular wollastonite can be used as coreinforcer in short fibre composites (Padma and Venkata, 2009; Mohan et al., 2006). Use of wollastonite in high fraction will reduce the cost of composite and improve tensile strength, impact properties and dimensional stability and yield Rao et al. (2011). High aspect ratio $(* 15)$ resulting on these wollastonite composites to resist machining and thus has greater surface area, better stress propagation (Sreenivasan et al., 2011; Rao et al., 2010). Reinforcement with wollastonite increases the starting crystallisation temperature and induces a shorter processing time in injection moulding and thus the effect of crystallinity of the composite for this reason the reinforcement of rotational moulded articles with wollastonite is of interest for research. These materials exhibits increase in flexural modulus, HDT, superior dimensional stability, reduced cost and ease processability. Certain mechanical properties such as strength or modulus of a hybrid system consisting of two single systems can be predicted by the rule of hybrid mixtures (RoHM) as explained earlier (Reddy et al., 2010; Reddy et al., 2009; 2008a; 2008b; Rajulu and Devi, 2007). The present work aims to develop chopped glass fibre and particulate type wollastonite reinforced epoxy composite. The composites were prepared by extrusion compounding and using injection moulding techniques. In the present research, the effects of hybridisation by chopped glass fibre and wollastonite on the tensile and flexural properties of the hybrid $\mathrm{EP} / \mathrm{GF} / \mathrm{W}$ composite were made. Since the mechanical properties of glass fibres and wollastonite differ greatly, the hybrid effect would likely to exist for their hybrid reinforced composites. The hybrid effects have been calculated using the rule of hybrid mixtures for the tensile strength, modulus, flexural strength and modulus.

\section{Materials and Methods}

The epoxy (Araldite-LY 556 and Amine Hardener- HY 951) employed in this study was Ciba-Geigy of India
Limited. In addition, the glass fibre (density: $350 \mathrm{~g} / \mathrm{m}^{2}$ ) was supplied by Saint Gobain Industries Ltd., Bangalore, India with an aspect ratio 250 . The grade of wollastonite (W) used for preparing different compositions was Fillex-11AB3 (surface treated), supplied by Wolkem India Limited. The total fibre volume fraction was fixed at $40 \%$. The compositions of prepared specimens are given in Table 1.

The extruder used was a twin screw extruder (JSW, Japan TEX-30A) with a diameter of $25 \mathrm{~mm}$ and machine capacity of $20 \mathrm{~kg} / \mathrm{h}$ having single feeding point. The set point temperatures were between 165 and $220^{\circ} \mathrm{C}$ for compounding. The composite was prepared by feeding the glass fibre and wollastonite in the polymer melt. The compounded extrudates were immediately quenched into water and cooled in air to ambient temperature. Then the extrudates strands were chopped into granules with the help of cutter and dried. All the specimens were then injection moulded using L\&T injection moulding machine with the parameters listed in Table 2. Test specimens for the evaluation of mechanical properties were prepared. The tensile, flexural and impact properties were determined using 5 samples of each composition.

Tensile strength, three point bending tests were carried out at par with ASTM D 53455. Tensile and flexural tests were performed on Instron universal testing machine (3369). Impact strength of samples was measured on the model number of machine Zwick according to ASTM D 53433. All the tests were accomplished at a room

Table 1. Various compositions prepared specimens

\begin{tabular}{llll}
\hline \hline Sample & EP (\% by wt. $)$ & GF (\% by wt. $)$ & W (\% by wt. $)$ \\
\hline $\mathrm{S}_{1}$ & 100 & 0 & 0 \\
$\mathrm{~S}_{2}$ & 60 & 40 & 0 \\
$\mathrm{~S}_{3}$ & 60 & 30 & 10 \\
$\mathrm{~S}_{4}$ & 60 & 20 & 20 \\
$\mathrm{~S}_{5}$ & 60 & 10 & 30 \\
$\mathrm{~S}_{6}$ & 60 & 0 & 40 \\
\hline \hline
\end{tabular}

Table 2. Injection moulding machine parameters for EP/GF/W composites

\begin{tabular}{llllll}
\hline \hline $\begin{array}{l}\text { Injection } \\
\text { pressure } \\
(\%)\end{array}$ & $\begin{array}{l}\text { Holding } \\
\text { pressure } \\
(\%)\end{array}$ & $\begin{array}{l}\text { Back } \\
\text { pressure }\end{array}$ & $\begin{array}{l}\text { Injection } \\
\text { speed }\end{array}$ & $\begin{array}{l}\text { Tempe- } \\
\text { rature } \\
\left({ }^{\circ} \mathrm{C}\right)\end{array}$ & $\begin{array}{l}\text { Pressure } \\
\left(\mathrm{N} / \mathrm{mm}^{2}\right)\end{array}$ \\
\hline 65 & 65 & 5.0 & 70 & 150 & $170-200$ \\
\hline \hline
\end{tabular}


temperature of $20^{\circ} \mathrm{C}$. At least, 5 samples were tested for each composition and results were averaged. Impact properties were measured in accordance with ASTM D256. The notched Izod test is best applied in determining the impact resistance for many parts with many sharp corners, such as ribs, intersecting walls and other stress concentrator components. The Izod strength of notched/ unnotched specimens were conducted (the impact energy used to break a notched/unnotched specimen is divided by the thickness of the specimen at the notch), expressed in kilojoules per meter $(\mathrm{kJ} / \mathrm{m})$. Scanning electron microscopy (SEM) studies of the fractured surface of the tensile specimen were carried out on a Jeol (6380LA, Japan). The specimen was sputter-coated with gold to increase surface conductivity. The length of 400-500 glass and wollastonite fibres from each sample were measured separately and recorded with Axiovision Rel 4.6 software.

\section{Results and Discussion}

The results obtained from mechanical tests are shown in Table 3. The results are also obtained graphically in Fig. 1(a-b). It has been found from data that with the incorporation of $40 \%$ glass fibre $\left(\mathrm{S}_{2}\right)$, the tensile strength, tensile modulus values increased sharply when compared to unfilled material indicating the stiffening effect of glass fibre. On the other hand with the incorporation of wollastonite from $10-30 \%$ by wt., the above values were found to decrease gradually with respect to $S_{2}$, indicating lower stiffening effect of wollastonite in comparison to glass fibre. When compared $\mathrm{S}_{1}$ with $\mathrm{S}_{6}$, it was observed that there is a little change in tensile strength value between $S_{1}$ and $S_{6}$, but the values of tensile modulus of $\mathrm{S}_{6}$ had been found higher than that of $\mathrm{S}_{1}$. The composites $\left(\mathrm{S}_{2}\right.$ to $\mathrm{S}_{6}$ ) yield had lower values of tensile modulus. On the basis of the above results, it was concluded that the addition of wollastonite content by reducing glass fibre partially, the degree of amorphous nature of epoxy

Table 3. Mechanical properties of EP/GF/W composites

\begin{tabular}{llll}
\hline \hline Sample & $\begin{array}{l}\text { Tensile } \\
\text { strength } \\
(\mathrm{MPa})\end{array}$ & $\begin{array}{l}\text { Tensile } \\
\text { modulus } \\
(\mathrm{MPa})\end{array}$ & $\begin{array}{l}\text { Elongation } \\
\text { at max. force } \\
(\%)\end{array}$ \\
\hline $\mathrm{S}_{1}$ & 46.2 & 451.6 & 13.1 \\
$\mathrm{~S}_{2}$ & 50.5 & 680.2 & 8.2 \\
$\mathrm{~S}_{3}$ & 47.7 & 593.4 & 9.4 \\
$\mathrm{~S}_{4}$ & 47.0 & 600.7 & 8.6 \\
$\mathrm{~S}_{5}$ & 42.2 & 617.0 & 8.4 \\
$\mathrm{~S}_{6}$ & 37.8 & 605.4 & 9.8 \\
\hline \hline
\end{tabular}

decreases. Tensile stress strain curves of hybrid composites exhibit brittle fracture and show linear deformation under high stress. This non-linear deformation behaviour may be related to (1) interfacial microfailure at the fibre ends would have occur in the composites, (2) the microfailure propagates along the fibre lengths, (3) plastic deformation bands in the matrix were observed, and (4) crack opening occurs in the band and the crack grows slowly through the band as observed by Rajulu and Devi (2007). Finally, the catastrophic crack propagation takes place through the matrix pulling out the fibres from the matrix. The curves shift from right side to left side as the relative
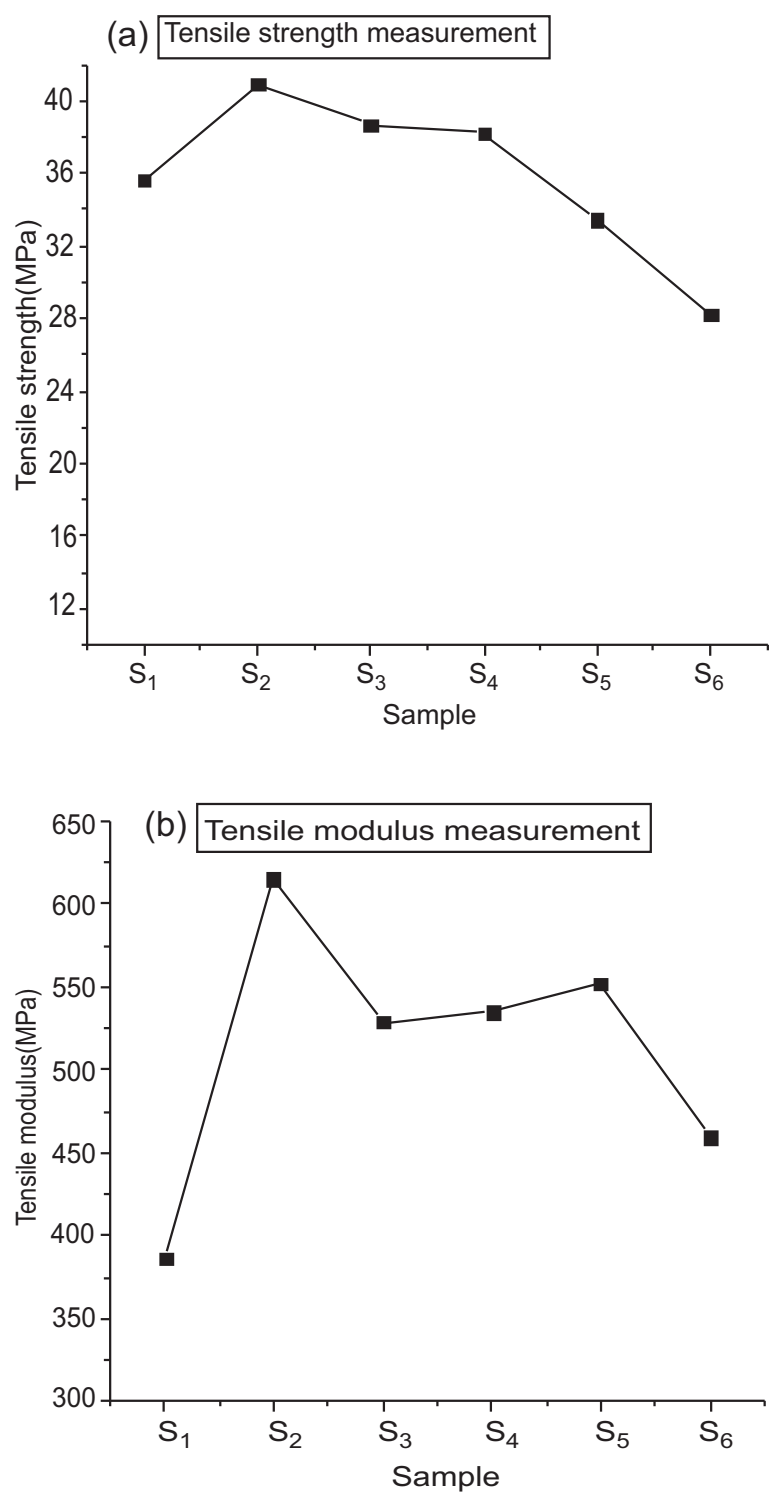

Fig. 1(a-b). Tensile (a) strength and (b) modulus measurements of samples. 
wollastonite fibre volume fraction increases. This is due to the fact that the modulus of wollastonite fibres is higher than the matrix but when compared to the glass fibre composite, the modulus shows a slight change with the increase in relative wollastonite volume fraction (Reddy et al., 2009). Moreover, the failure strain of the hybrid composites increases with increase in relative wollastonite fibre volume fraction as shown in Fig. 2. This may be partially attributed to the less brittle nature of wollastonite fibre compared to glass fibre. Furthermore, as the wollastonite fibre volume increases there is no significant increase in the strength of the composites.

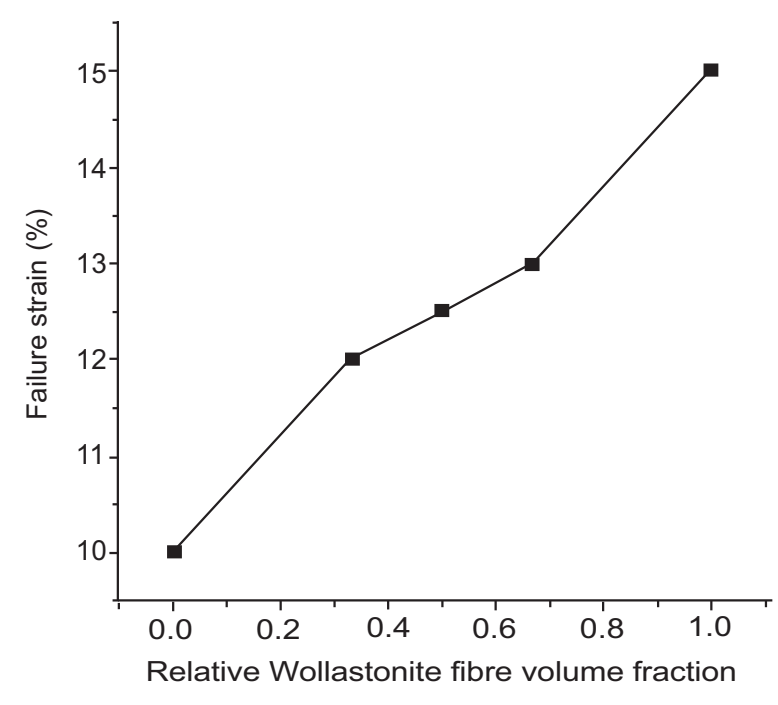

Fig. 2. Measurements of relative fibre volume fractions of failure strain of the samples.

Figure 3(a-b) represents the SEM micrographs of fracture surfaces of hybrid composites $\mathrm{S}_{4}$ and $\mathrm{S}_{6}$. The brittle fracture can be easily seen in the composites. It is observed that the short glass fibre and wollastonite were intimately mixed in the matrix and were distinguishable. Both the figures show that most of the glass fibres are pulled out and preferentially aligned in flow direction for these injection moulded specimens.

The orientation of fibres is observed morphologically on the specimen sections as shown in Fig. 3 which is the micrographs selected arbitrarily but is a typical one. For both single fibre reinforced and hybrid composites, the fibres are preferentially aligned along the flow direction. This has also been observed in earlier shortfibre studied (Kumar et al., 2011a; 2011b; 2011c). Fibre length measurements were performed by following manually fibre
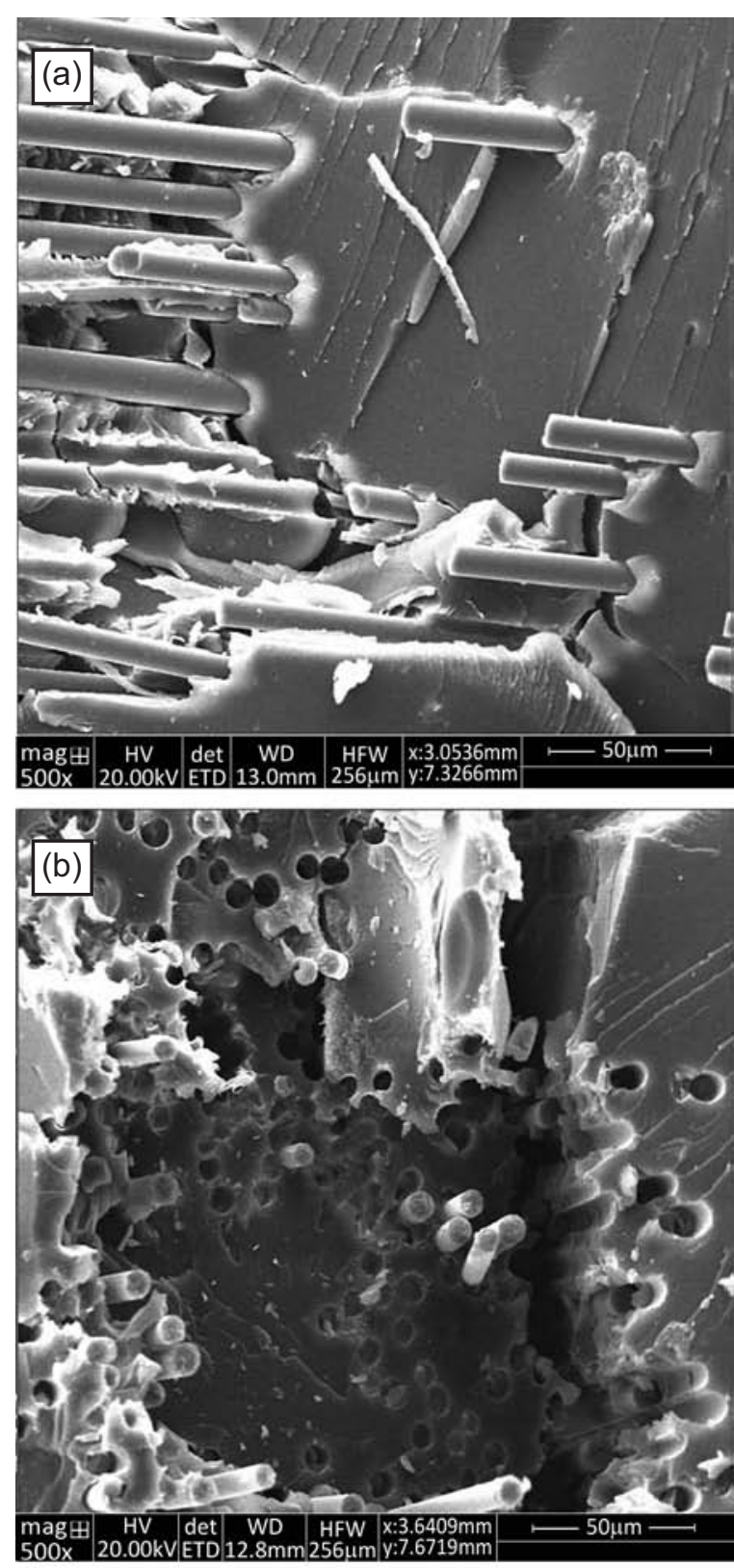

Fig. 3(a-b). SEM images of (a) sample $\mathrm{S}_{4}$, and (b) sample $\mathrm{S}_{6}$.

image traces from morphological pictures using Zeiss computerised microscope.

The effect of relative wollastonite fibre volume fraction on the mean wollastonite and glass fibre lengths is presented in Table 4 and Fig. 4, where the total glass and wollastonite fibre fraction is fixed at $40 \%$. It is of interest to note while observing the trends in mean fibre lengths of both the fibres that with the increase of relative wollastonite fibre volume fraction decreases the mean 
Table 4. Relative frequencies of EP/GF/W composites

\begin{tabular}{|c|c|c|c|c|c|c|c|c|}
\hline \multirow[t]{2}{*}{$\begin{array}{l}\text { Length } \\
\text { classes }(\mu \mathrm{m})\end{array}$} & \multirow{2}{*}{$\begin{array}{l}\mathrm{Vf}(\mathrm{GF})=40 \% \\
\mathrm{Vf}(\mathrm{W})=0 \% \\
\mathrm{GF}\end{array}$} & \multicolumn{2}{|c|}{$\begin{array}{l}V f(G F)=30 \% \\
V f(W)=10 \%\end{array}$} & \multicolumn{2}{|c|}{$\begin{array}{l}V f(G F)=20 \% \\
V f(W)=20 \%\end{array}$} & \multicolumn{2}{|c|}{$\begin{array}{l}\mathrm{Vf}(\mathrm{GF})=10 \% \\
\mathrm{Vf}(\mathrm{W})=30 \%\end{array}$} & \multirow{2}{*}{$\begin{array}{l}\mathrm{Vf}(\mathrm{GF})=0 \% \\
\mathrm{Vf}(\mathrm{W})=40 \% \\
\mathrm{~W}\end{array}$} \\
\hline & & GF & $\mathrm{W}$ & GF & W & GF & W & \\
\hline $0-2$ & 0 & 0 & 0 & 0 & 0 & 0 & 0 & 0 \\
\hline $2-4$ & 0 & 0 & 0 & 0 & 0 & 0 & 0 & 0 \\
\hline $4-6$ & 0 & 0 & 0.04 & 0 & 0.04 & 0 & 0 & 0 \\
\hline $6-10$ & 0 & 0 & 0.18 & 0 & 0.04 & 0 & 0.12 & 0.14 \\
\hline $10-20$ & 0.10 & 0.06 & 0.40 & 0.08 & 0.18 & 0.08 & 0.22 & 0.24 \\
\hline $20-40$ & 0.16 & 0.16 & 0.44 & 0.06 & 0.24 & 0.04 & 0.32 & 0.28 \\
\hline $40-60$ & 0.2 & 0.14 & 0.04 & 0.16 & 0.28 & 0.14 & 0.28 & 0.18 \\
\hline $60-80$ & 0.22 & 0.36 & 0 & 0.18 & 0.08 & 0.18 & 0.08 & 0.1 \\
\hline $80-100$ & 0.16 & 0.08 & 0 & 0.18 & 0.1 & 0.16 & 0.1 & 0.1 \\
\hline $100-120$ & 0.16 & 0.18 & 0 & 0.22 & 0 & 0.28 & 0 & 0.04 \\
\hline $120-140$ & 0.04 & 0.06 & 0 & 0.08 & 0 & 0.08 & 0 & 0.04 \\
\hline $140-160$ & 0.06 & 0.06 & 0 & 0.14 & 0 & 0.14 & 0 & 0 \\
\hline $160-180$ & 0.04 & 0.04 & 0 & 0.04 & 0 & 0.04 & 0 & 0 \\
\hline $180-200$ & 0.04 & 0.06 & 0 & 0.04 & 0 & 0.04 & 0 & 0 \\
\hline $200-260$ & 0.04 & 0.04 & 0 & 0.04 & 0 & 0.04 & 0 & 0 \\
\hline$>260$ & 0 & 0 & 0 & 0 & 0 & 0 & 0 & 0 \\
\hline $\begin{array}{l}\text { Mean fibre } \\
\text { length }(\mu \mathrm{m})\end{array}$ & 78.5 & 110.2 & 25.36 & 98.5 & 40.5 & 103.8 & 42.5 & 48.62 \\
\hline
\end{tabular}

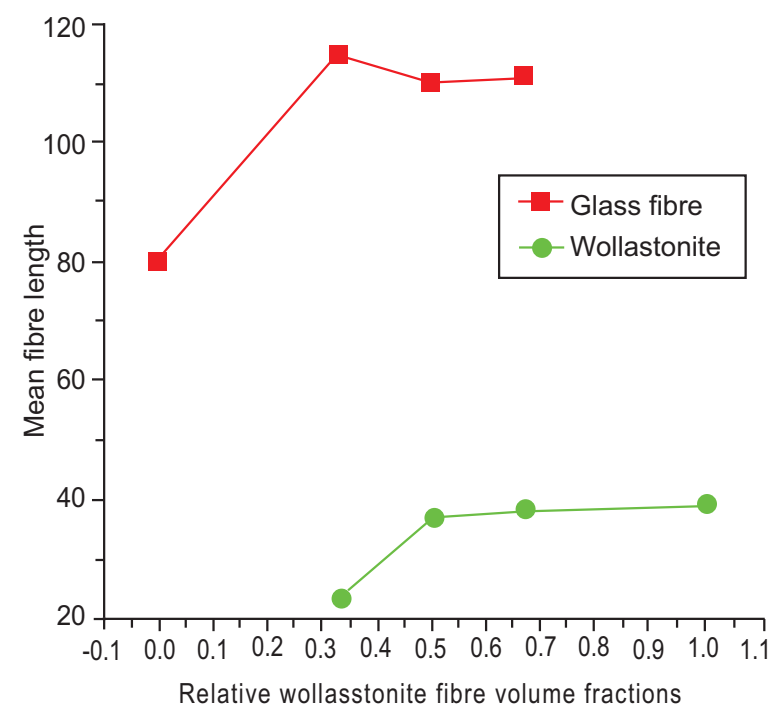

Fig. 4. Relative wollastonite fibre volume fraction $\mathrm{Vf}$ (wollastonite)/Vf(total).

fibre length relative than the wollastonite fibre due to wollastonite interaction. The glass and wollastonite fibre length distributions are presented in Fig. 5(a-b) which show that, fibre length distributions of both glass and wollastonite fibres shift towards left side as the relative wollastonite fibre volume fraction increases. This figure depicts the cumulative distribution of the fillers in matrix that leads to further study of the fibre distribution. Figure 5 show the results of the RoHM prediction and the strength of hybrid $\mathrm{EP} / \mathrm{GF} / \mathrm{W}$ composites.

Figure 6 shows the results of the tensile strength of the hybrid composite. It was observed that, ultimate strength was significantly improved by the incorporation of glass and mineral fibres. Since the fibres were preferentially aligned in flow direction for these injection moulded specimens (see SEMs), in broader view the fibre orientation can be assumed roughly unchanged with the fibre volume fraction. When the relative wollastonite fibre volume fraction increased, there is a slight variation in the mean glass and wollastonite fibre lengths. The changes in fibre length were considered to affect the strength of hybrid composites which was predicted using RoHM as described earlier by Reddy et al. (2011). The predicted values of the strength for hybrid composite are presented in Fig. 6a. It can be seen that the experimental values of the ultimate strength of the hybrid composite lie slightly above the predicted values. Thus strength studies exhibits a positive deviation from predicted volumes which is evident by fibre addition. Since the wollastonite fibre is slightly less stiff as compared to glass fibre and the mean aspect ratios of wollastonite fiber composites were lesser than those of glass fibers. Thus according to the stress 

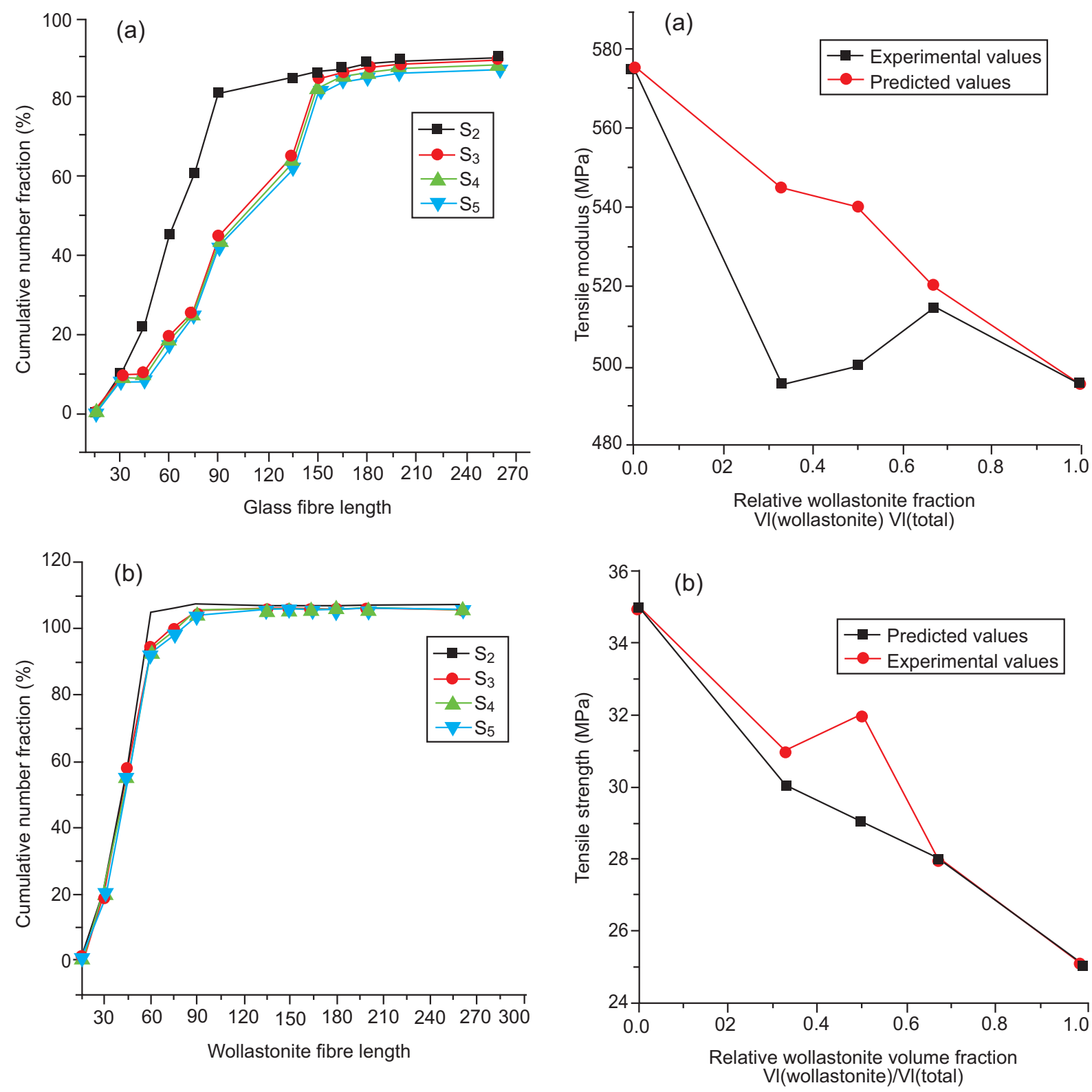

Fig. 5(a-b). (a) Glass fibre and (b) wollastonite fibre length distributions for hybrid, $\mathrm{SGF} / \mathrm{W} / \mathrm{EP}$ composites.

transfer theory (Reddy et al., 2009) interfacial debonding would have taken place first at wollastonite fibre ends. Leading to micro crack creation, it was observed that wollastonite fibres are the source for the micro cracks. As the applied tensile strain or load is increased these cracks propagate along the fibre length and also across neighbouring matrix. In the presence of glass fibres these cracks would be bridged by these mineral fibres, allowing the wollastonite fibres to have a slightly larger contribution to the tensile strength of the hybrid composites than that

of single wollastonite reinforced composites. As a result, a slight encouraging strength of hybrid composites is observed with the addition of these fibres. Figure 6(b) shows the case of tensile modulus. Since glass fibres are stiffer than wollastonite, modulus was observed to increase with the $100 \%$ relative volume of glass fibre and as wollastonite replaces glass fibre partially, composite modulus decreases with increasing relative wollastonite volume fraction. It can be observed from the figure that modulus of hybrid composites is greatly improved by 
the addition of both glass fibres and wollastonite fibres (the matrix modulus is $386.3 \mathrm{MPa}$ ). The modulus decreases slightly with the increase in relative wollastonite volume fraction. The predicted values according to mixture rule lie above the experimental values and it indicates that the modulus exhibits a negative deviation from the mixture rule.

\section{Conclusion}

The mechanical properties of injection moulded hybrid epoxy composites reinforced with short glass fibres and wollastonite fibres have been investigated. The results have shown that the tensile strength, tensile modulus, flexural strength, flexural modulus and impact strength of hybrid composites are in close agreement with composites. The elongation at ultimate load and failure strain of the hybrid composites increases slightly with increase in relative wollastonite fibre volume fraction. The effects of fibre reinforced have been studied on the tensile properties of the hybrid composites. A positive effect had been observed in the ultimate strength while negative effect was noted for the tensile modulus.

\section{Acknowledgement}

Authors pay gratitude for Department of Polymer Science and Technology, and Department of Pharmacy at S. K. University Anantapur, India for providing instruments.

\section{References}

Dani, J., Rajulu, A.V., Guduri, B.R. 2008. Tensile properties of polycarbonate-coated natural fabric hildegardia populifolia. Journal of Reinforced Plastics and Technology, 27: 1833-1838.

Dauda, S.B., Olutunde, O., Prasad, P. 2009. Characterizing mechanical properties of braided and woven textile composite beams. Applied Composite Materials, 16: 15-21.

Jayaramudu, J., Reddy, O.K., Maheswari, U.C., Reddy, J.P.D., Rajulu, V.A. 2009. Tensile properties and thermal degradation parameters of polyalthia cerasoides natural fabric reinforcement. Journal of Reinforced Plastics and Composites, 28: 21772181.

John, K., Naidu, V.S. 2007. Chemical resistance of sisal/glass reinforced unsaturated polyester hybrid composites. Journal of Reinforced Plastic Composites, 26: 373-376.
Kumar, A.M., Reddy, R.G., Reddy, H.G., Chakradhar, K.V.P., Reddy, N.B., Reddy, S.N. 2011a. Mechanical properties of randomly oriented short sansevieria trifasciata fibre/epoxy composites. International Journal of Fibre and Textile Research, 1: 6-10.

Kumar, A.M., Reddy, G.R., Reddy, H.K., Reddy, V.M.Y., Reddy, R.P., Reddy, S.N. 2011b. Fabrication and performance of hybrid betel nut (Areca catechu) short fibre/Sansevieria cylindrica (agavaceae) composite. The Indian Journal of Materials Science, 53: 375-386.

Kumar, A.M., Reddy, H.K., Reddy, G.R., Reddy, V.M.Y., Reddy, S.N. 2011c. Tensile, thermal properties \& chemical resistance of epoxy/hybrid fibre composites (glass/jute) filled with silica powder. Indian Journal of Macromolecules, 24: 241-249.

Kumar, A.M., Reddy, G.R., Bharathi, S.Y., Naidu, S.V., Naidu, N.P.V. 2010. Frictional coefficient, hardness, impact strength and chemical resistance of reinforced sisal-glass fiber epoxy hybrid composites. Journal of Composite Materials, 46: 3195-3202.

Mishra, S.C., Aireddy, H. 2011. Evaluation of dielectric behavior of bio-waste reinforced polymer composite. Journal of Reinforced Plastics \& Composites, 30: 134-141.

Mohan, T.P., Ramesh, K.M., Velmurugan, R. 2006. Thermal, mechanical and vibration characteristics of epoxy-clay nanocomposites. Journal of Material Science, 41: 5915-5925.

Padma, V.T., Naidu, V.S. 2009. Chemical resistance and tensile properties of sisal/glass fibres. Indian Journal of Fibre and Textile Research, 23: 128-132.

Rajulu, V.A., Devi, R.R. 2007. Tensile properties of ridge gourd/phenolic composites and glass/ridge gourd/phenolic hybrid composites. Journal of Reinforced Composites and Plastics, 26: 629-638.

Rao, R.H., Kumar, A.M., Reddy, R.G. 2011. Hybrid composites: Effect of fibers on mechanical properties. International Journal of Macromolecular Science, 1: 9-14.

Rao, R.H., Rajulu, V.A., Reddy, R.G., Reddy, H.K. 2010. Flexural and compressive properties of bamboo and glass fiber-reinforced epoxy hybrid composites. Journal of Reinforced Plastics and Composites, 29: 1446-1450.

Reddy, R.G., Kumar, A.M., Chakradhar, K.V.P. 2011. Fabrication and performance of hybrid betel nut (Areca catechu) short fiber/sansevieria cylindrica 
(agavaceae) epoxy composites. International Journal of Materials and Biomaterials Applications, 1: 6-13.

Reddy, V.S.E., Rajulu, V.A., Reddy, H.K., Reddy, R.G. 2010. Chemical resistance and tensile properties of glass and bamboo fibres reinforced polyester hybrid composites. Journal of Reinforced Plastics and Composites, 29: 2119-2123.

Reddy, V.G., Rani, S.T., Rao, C.K., Naidu, V.S. 2009. Flexural, compressive and interlaminar shear strength properties of kapok/glass composites. Journal of Reinforced Plastics and Composites, 28: 16651677.

Reddy, V.G., Naidu, V.S., Rani, S.T. 2008a. Impact properties of kapok based unsaturated polyester hybrid composites. Journal of Reinforced Plastics and Composites, 27: 1789-1804.

Reddy, V.G., Naidu, V.S., Rani, S.T. 2008b. Kapok/glass polyester hybrid composites: tensile and hardness properties. Journal of Reinforced Plastics and Composites, 27: 1775-1787.

Sreenivasan, V.S., Somasundaram, S., Ravindran, D., Manikandan, V., Narayanasamy, R. 2011. Microstructural physico-chemical and mechanical characterization of Sansevieria cylindrica fibres: an exploratory investigation. Materials and Design, 32: 453-461. 